\title{
The challenge continues: A multiphase, multidisciplinary approach is necessary for providing the best quality of life in geriatric patients after cardiac surgery
}

\author{
Ko Bando, MD, PhD
}

From the Department of Cardiac Surgery, The Jikei University School of Medicine, Tokyo, Japan.

Disclosures: Author has nothing to disclose with regard to commercial support.

Received for publication June 20, 2017; accepted for publication June 30, 2017; available ahead of print Aug 3 , 2017.

Address for reprints: Ko Bando, MD, PhD, Department of Cardiac Surgery, The Jikei University School of Medicine, 3-25-8, Nishi Shimbashi, Minato-ku, Tokyo 105-8461, Japan (E-mail: kobando@jikei.ac.jp).

J Thorac Cardiovasc Surg 2017;154:1679-80

$0022-5223 / \$ 36.00$

Copyright (c) 2017 by The American Association for Thoracic Surgery

http://dx.doi.org/10.1016/j.jtcvs.2017.06.055

In the current era of cardiac surgery, geriatric patients represent the fastest growing population in Western countries and are at increased risk of prolonged hospitalization, ${ }^{1}$ mortality, and various morbidities early after surgery. Although the European System for Cardiac Operative Risk Evaluation II and the Society of Thoracic Surgeons risk scores have been widely accepted as the standards for evaluating perioperative mortality and morbidity in patients who undergo cardiac surgery, these risk models have major limitations. ${ }^{2,3}$

First, both risk assessment models were developed to predict only early mortality and morbidity, meaning that late outcomes including survival and functional status cannot be assessed. Second, both models were based on chronologic age, medical diagnoses, and comorbidities; the biological status of an elderly patient, including frailty, was not well incorporated. Third, both models include primarily preoperative indices, so precise intraoperative factors and postoperative intensive care unit (ICU) events were not taken into account.

In their article in this issue of the Journal titled, "Outcomes of Octogenarians Discharged From Hospital After Prolonged Intensive Care Unit Length of Stay After Cardiac Surgery," Arora and colleagues ${ }^{4}$ clarified the impact of a prolonged ICU length of stay (LOS) on survival and functional survival (ie, noninstitutional survival) and rehospitalization for octogenarian patients. ${ }^{4}$ The authors should be commended for undertaking this timely and clinically relevant study primarily because it represents one of the first attempts to answer the questions that the European System for Cardiac Operative Risk Evaluation II and Society of Thoracic Surgeons score cannot. For geriatric patients and their families, what is more relevant to them is not whether they will survive the operation, but whether they can eventually go home, whether they will be able to sustain themselves independently, and how much they should expect to pay for their surgery and postoperative care.

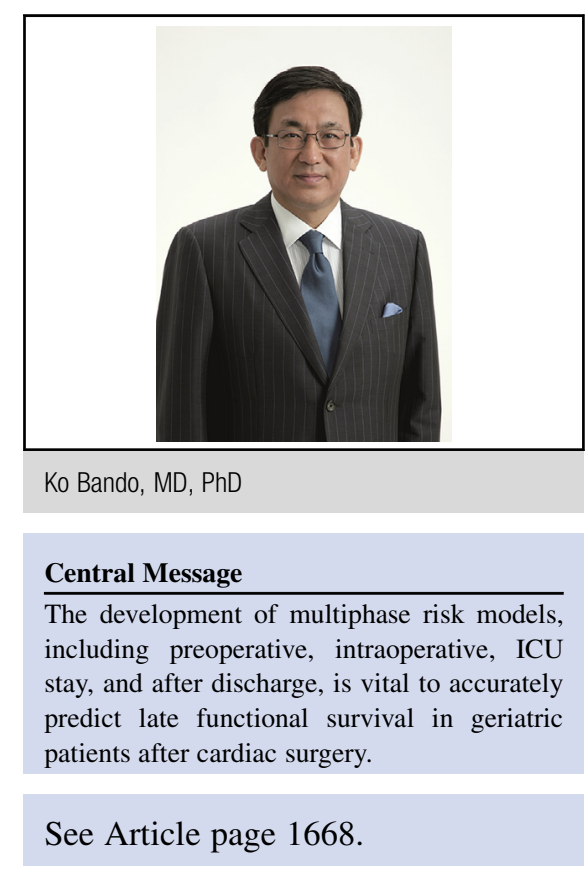

While focusing on the length of ICU stay, Arora and colleagues ${ }^{4}$ found that octogenarian patients with prolonged ICU LOS had a lower rate of functional survival at 1 and 5 years after surgery compared with those without prolonged ICU LOS, and those patients without prolonged ICU LOS had higher survival after cardiac surgery compared with the age- and sex-matched general population. These findings remind us that it is important to answer the following 2 questions: What are the risk factors for prolonged ICU LOS in octogenarian patients who underwent cardiac surgery? and How we can avoid those risk factors?

Their article included several important tips that require further investigation. ${ }^{4}$ Preoperatively, patients who experienced a prolonged ICU LOS more frequently had congestive heart failure, cardiogenic shock, and nonelective surgery. ${ }^{4}$ Therefore, we need to find out why physicians were reluctant to refer patients for surgery before the development of congestive heart failure or cardiogenic shock and before emergency surgery was necessary and how we can encourage them to refer these patients in an appropriate time period. Intraoperatively, they also found that geriatric patients with prolonged ICU LOS had more complex procedures and prolonged 
crossclamp and cardiopulmonary bypass times. ${ }^{4}$ Further precise intraoperative assessment is needed to find out how can we shorten the crossclamp and bypass times and which adverse events and unplanned procedures have a significant impact on prolonged ICU LOS. Quality improvement techniques aimed at avoiding consequences of precursor events might reduce the ICU LOS and subsequent late surgical outcomes in those geriatric patients. ${ }^{5}$ Arora and colleagues ${ }^{4}$ also found that after these patients were discharged, a lack of access to timely physician visits was associated with a significantly lower rate of functional survival. On the basis of these findings, I propose that multiphase phase risk models, including preoperative, intraoperative, during ICU stay, and after discharge, are certainly warranted to accurately predict late survival and functional survival in geriatric patients who underwent cardiac surgery. ${ }^{6}$ Moreover, a multidisciplinary team approach should be mandatory for providing the best functional outcomes in these geriatric patients after cardiac surgery. The challenge of handling these multiple tasks continues.

\section{References}

1. Sepehri A, Beggs T, Hassan A, Rigatto C, Shaw-Daigle C, Tangri N, et al. The impact of frailty on outcomes after cardiac surgery: a systematic review. J Thorac Cardiovasc Surg. 2014;148:3110-7.

2. Jin R, Furnary AP, Fine SC, Blackstone EH, Grunkemeier GL. Using Society of Thoracic Surgeons risk models for risk-adjusting cardiac surgery results. Ann Thorac Surg. 2010;89:677-82.

3. Nashef SA, Roques F, Sharples LD, Nilsson J, Smith C, Goldstone AR, et al. EuroSCORE II. Eur J Cardiothorac Surg. 2012;41:734-44.

4. Arora RC, Manji RA, Singal RK, Hiebert B, Menkis AH. Outcomes of octogenarians discharged from the hospital after prolonged intensive care unit length of stay after cardiac surgery. J Thorac Cardiovasc Surg. 2017;154:1668-78.

5. Sang SLW, Chturvedi RK, Iqbal S, Lachapelle K, de Varennes B. Functional quality of life following open valve surgery in high-risk octogenarians. J Card Surg. 2012;27:408-14.

6. Herman CR, Legare JF, Levy A, Buth KJ, Baskett R. Are intraoperative precursor events associated with postoperative major adverse events? J Thorac Cardiovasc Surg. 2014;147:1499-504. 